\title{
Physical activity and subarachnoid haemorrhage: a population based case-control study
}

\author{
J R Fann, W A Kukull, W J Katon, W T Longstreth Jr
}

\begin{abstract}
Objective-To evaluate physical activity as a risk factor for subarachnoid haemorrhage.

Methods-A population based casecontrol study in King County, Washington. A standardised, personal interview was used to determine physical activity during the past year and at the onset of the bleed for case patients and a similar reference time for control subjects. Conditional logistic regression and a case cross over analysis were performed in which each case patient served as his or her own control. Subjects were 149 men and women with incident, spontaneous subarachnoid haemorrhage and two control subjects per case patient. Control subjects were identified through random digit dialing and matched on age, sex, and respondent type. Results-Four of the $149(2.7 \%)$ case patients were engaged in vigorous physical activity at the time of their subarachnoid haemorrhage. With those who were engaged in non-vigorous or no physical activity serving as the reference group, the relative risk of sustaining a subarachnoid haemorrhage for those engaged in vigorous physical activity was 11.6 (95\% confidence interval $(95 \% \mathrm{CI}) 1.2-113.2)$. In the case cross over analysis, the relative risk was 15.0 (95\% CI 4.3-52.2). Higher levels of long term regular physical activity over the past year were associated with a lower, but not statistically significant, risk of subarachnoid haemorrhage (test for trend, $\mathrm{p}=0.3$ ).

Conclusion-The risk of subarachnoid haemorrhage is increased during vigorous physical activity, although only a few result from this mechanism.

(f Neurol Neurosurg Psychiatry 2000;69:768-772)
\end{abstract}

Keywords: subarachnoid haemorrhage; physical activity; risk factors

Neurology, School of

Medicine

W T Longstreth Jr

Department of Epidemiology, School of Public Health and Community Medicine W A Kukull

W T Longstreth Jr

Correspondence to: Dr Jesse R Fann

fann@u.washington.edu

Received 28 February 2000 and in revised form

30 June 2000

Accepted 11 July 2000 and long term effects of physical activity on the risk of subarachnoid haemorrhage, we examined data obtained as part of a population based case-control study. ${ }^{16}{ }^{17}$

\section{Methods}

Patients in King County, Washington, were recruited over a 2 year period for a population based case-control study of risk factors for spontaneous subarachnoid haemorrhage. The source of the haemorrhage was either from an aneurysm or unknown. Patients whose bleed was known to have originated from a source other than an aneurysm were excluded. Two control subjects were identified using random digit dialing for each case patient. Control subjects were matched to case patients by sex and age within 5 years. The study is described in detail elsewhere ${ }^{1617}$ and was approved by the University of Washington human subjects committee.

A standardised in person interview was conducted with the patients if possible, but always with their proxies as well as the two control subjects and their proxies. Some questions in the interview were linked to a reference time. For the case patients, the reference time was when the initial subarachnoid haemorrhage occurred. For the control subjects, the reference time was the same time of day and day of the week as their matched case patients, but in the week before the interview of the control subject.

Participants were interviewed about their lifetime use of cigarettes, about their use of alcohol and stimulant drugs in the year before the reference date, and whether a physician had ever told them that they had hypertension. ${ }^{16}$ Participants were also asked: (1) what physical activities they had performed on a regular basis, at least twice a month, during their leisure time in the 12 months before the reference date; (2) how many times a month and how many months they engaged in each activity; and (3) how many minutes they spent at each activity. They were then asked if they were engaged in any physical activities during the reference time and, if so, which one.

All physical activities were assigned an intensity unit based on their rate of energy expenditure, expressed as metabolic equivalents (METs). ${ }^{18}$ One MET is defined as the energy expended/minute by a subject sitting quietly and is equivalent to 1 kilocalorie/ kilogram body weight/ hour ( $\mathrm{kcal} / \mathrm{kg} / \mathrm{h})$. Participants were said to engage in vigorous physical activity if the activity had a MET value of 6 or greater. ${ }^{19}$ Activities at reference time for which MET values were not available were 
coded as being non-vigorous (MET <6). By multiplying the MET value by the body weight in $\mathrm{kg}$ and the duration of activity in hours, we could estimate an energy (kcal) expenditure specific to a person's body weight. Such measures of physical activity have been found to correlate well with physical fitness. ${ }^{20}$ Physical activity was quantified by several different methods. Acute physical activity at reference time was categorised as non-vigorous or no activity versus vigorous activity. Long term regular physical activity over the 12 months before the reference time was quantified as $\mathrm{kcal} /$ week engaged in all physical activity.

STATISTICAL ANALYSIS

When the patient was able to provide information about exposures, interviews from the two matched control subjects themselves were used. When the patient was unable to provide information, due to disability or death, interviews from the patient's proxy and the proxies for the two matched control subjects were used. Multiple conditional logistic regression was used to determine the relation between the various measures of physical activity and subarachnoid haemorrhage, taking into account matching on sex, age, and respondent type. Odds ratios and 95\% confidence intervals (95\% CIs) were calculated to estimate relative risks. In the analysis, education level, marital status, race, smoking history (never, former, current), alcohol use (non-drinker, light, moderate, heavy drinker), stimulant drug use (never, ever), hypertension status (never, evernot treated, ever treated), body mass index, and long term regular physical activity during the past year (kcal/week) were examined for potential confounding and effect modification of the relation between physical activity and subarachnoid haemorrhage. All logistic regression analyses were performed using the Epidemiologic Graphics, Estimation, and Testing (EGRET) software. ${ }^{21}$

We also performed a case cross over analysis, a self matched method developed to identify transient effects on the risk of acute events which only employs information from case patients. ${ }^{22}$ The person-time spent in vigorous physical activity (exposure) was calculated by multiplying the reported average duration of vigorous physical activity by the number of times a person was engaged in the activity/ month by the number of months engaged in the activity. The unit of time used was 15 minute blocks. The person-time not spent in vigorous physical activity (unexposed) was calculated by subtracting the exposed person-time in 15 minute blocks from the total number of 15 minute blocks in a year-namely, 35040 . The hazard period was defined as the $15 \mathrm{~min}$ utes before the onset of subarachnoid haemorrhage. For each patient, the observed and expected odds of vigorous physical activity during the hazard period were calculated. The observed odds was 1:0 for the patient engaged and $0: 1$ for the patient not engaged in vigorous physical activity during the hazard period. The expected odds was $\mathrm{x}: \mathrm{y}$, where $\mathrm{x}$ was the number of 15 minute blocks during the past year in which a patient was engaged in vigorous physical activity, and $\mathrm{y}$ in which a patient was not engaged in vigorous activity. Thus, $\mathrm{x}$ : $\mathrm{y}$ would be the odds of a patient performing vigorous physical activity during the hazard period, based on the usual frequency of vigorous physical activity in the previous year. The Mantel-Haenszel estimate of relative risk can be calculated where the numerator is the algebraic sum of $y$ in patients reporting vigorous physical activity during the hazard period and the denominator is the sum of $\mathrm{x}$ in patients reporting no vigorous physical activity during the hazard period. Thus, the risk ratio (RR) indicates the risk of having a subarachnoid haemorrhage during a period of vigorous physical activity compared with the risk during periods of non-vigorous or no physical activity. ${ }^{23}$

\section{Results}

During the 2 years of the study, 149 incident patients with spontaneous subarachnoid haemorrhage were enrolled and interviewed. Detailed information, including evaluation, treatment, and outcome of these patients, is described elsewhere. ${ }^{17}$ Of the 149 patients enrolled in the study, 74 could be interviewed. The remaining 75 case patients could not be interviewed because of death or disability, and their proxies were interviewed instead. A detailed description of the completeness and accuracy of interview data from proxy respondents is found elsewhere. ${ }^{24}$ Through random digit dialing, 298 matched control subjects were enrolled and interviewed. Mean (SD) age was 56.3 (16.7) years for case patients and 56.2 (16.5) years for control subjects. Sixty nine per cent of subjects were women. White people comprised $86.6 \%$ of case patients and $91.9 \%$ of control subjects. Education of less than 12 years applied to $19.7 \%$ of case patients and $12.7 \%$ of control subjects.

Physical activities immediately before the bleed were reported by 38 of $149(26 \%)$ case patients and are listed in table 1, along with their MET values when known. In the case-control analysis, the risk of subarachnoid haemorrhage was increased for those engaged

Table 1 List of physical activities and their metabolic equivalents (METs) for 38 case patients who reported being physically active during the 15 minutes before the onset of subarachnoid haemorrhage

\begin{tabular}{lll}
\hline Physical activity & Number & METs* \\
\hline Vigorous: & 2 & 8 \\
Running & 1 & 7 \\
Skating & 1 & 7 \\
$\quad$ Soccer & & \\
Non-vigorous: & 1 & 5 \\
Golf (walking) & 4 & 4.5 \\
Gardening & 1 & 4.5 \\
Home exercise & 1 & 3 \\
Carpentry & 6 & 1.3 \\
Sexual intercourse & 2 & 1.0 \\
Bowel movement & 19 & - \\
Other† & 19 &
\end{tabular}

${ }^{\star}$ One metabolic equivalent (MET) equals $1 \mathrm{kcal} / \mathrm{kg} / \mathrm{h}$. Vigorous physical activity is defined as METs $\geqslant 6$. For "other," MET value unavailable and assumed to be non-vigorous (METs <6). †Other activities included squatting, straining, bending, coughing, sneezing, work related activities, and other recreational and non-recreational activities. 
Table 2 Risk of subarachnoid haemorrhage associated with vigorous physical activity using logistic regression and case cross over analyses

\begin{tabular}{|c|c|c|c|c|c|c|}
\hline & \multicolumn{6}{|c|}{ Logistic regression analysis } \\
\hline & \multicolumn{2}{|c|}{ Case patients $n=149$} & \multicolumn{2}{|c|}{ Control subjects $n=298$} & \multicolumn{2}{|c|}{ Adjusted relative risk ${ }^{*}$} \\
\hline & $n$ & $\%$ & $\bar{n}$ & $\%$ & $R R$ & $95 \% C I$ \\
\hline \multirow[t]{4}{*}{$\begin{array}{l}\text { Non-vigorous or no physical activity at reference time } \\
\text { Vigorous physical activity at reference time } \\
\text { Missing }\end{array}$} & $\begin{array}{l}138 \\
4 \\
7\end{array}$ & $\begin{array}{l}92.6 \\
2.7 \\
4.7\end{array}$ & $\begin{array}{l}280 \\
1 \\
17\end{array}$ & $\begin{array}{l}94 \\
.3 \\
5.7\end{array}$ & $\begin{array}{l}1.0 \\
11.6\end{array}$ & $1.2-113.2$ \\
\hline & \multicolumn{6}{|c|}{ Case cross over analysis } \\
\hline & & \multirow{2}{*}{\multicolumn{3}{|c|}{$\begin{array}{l}\text { No with vigorous activity }<15 \\
\text { minutes before onset }\end{array}$}} & \multicolumn{2}{|c|}{ Relative riskt } \\
\hline & No & & & & $R R$ & $95 \% C I$ \\
\hline All cases & 149 & 4 & & & 15.0 & $4.3-52.2$ \\
\hline
\end{tabular}

*Adjusted relative risk (RR) and 95\% CIs were derived from conditional logistic regression, taking into account matching on age, sex, and respondent type and adjusting for hypertension status and long term regular physical activity during past year (kcal/week). $+R R$ and $95 \%$ CI of having a subarachnoid haemorrhage during a period of vigorous physical activity compared with a period of non-vigorous or no physical activity were derived from the Mantel-Haenszel estimate.

in vigorous physical activity at reference time compared with those engaged in non-vigorous or no physical activity (RR $11.6 ; 95 \%$ CI 1.2 113.2, table 2). Similar results were found in the case cross over analysis, in which each case patient served as his or her own control (see appendix for details on calculation of RR). The RR was 15.0 (95\% CI, 4.3-52.2) of having a subarachnoid haemorrhage during a 15 minute period of vigorous physical activity compared with a 15 minute period of non-vigorous or no physical activity.

Higher long term regular physical activity tended to be protective against spontaneous subarachnoid haemorrhage, but none of the RRs or the test for trend were significant (table 3). Exploration for confounding showed smoking status as the only confounder. When examining the risk for subarachnoid haemorrhage for "somewhat active" and "very active" persons compared with "inactive" persons according to age, sex, hypertension status, body mass index, and smoking status, there was no evidence for effect modification (tests for heterogeneity all $\mathrm{p}>0.05$ ).

\section{Discussion}

Although only a few subjects in this study engaged in vigorous physical activity at the reference time, we found a strong association between spontaneous subarachnoid haemorrhage and acute vigorous physical activity which could not be explained by potential confounding factors, including hypertension or baseline physical activity. This association was

Table 3 Risk of subarachnoid haemorrhage associated with different levels of long term regular physical activity during the previous year

\begin{tabular}{|c|c|c|c|c|c|c|}
\hline & \multicolumn{2}{|c|}{ Case patients $n=149$} & \multicolumn{2}{|c|}{$\begin{array}{l}\text { Control subjects } \\
n=298\end{array}$} & \multicolumn{2}{|c|}{$\begin{array}{l}\text { Adjusted relative } \\
\text { risk }\end{array}$} \\
\hline & $n$ & $\%$ & $n$ & $\%$ & $R R$ & $95 \% C I$ \\
\hline \multicolumn{7}{|c|}{ kcal/week engaged in all physical activity: $†$} \\
\hline Inactive & 63 & 42.3 & 91 & 30.5 & 1.0 & - \\
\hline Somewhat active & 44 & 29.5 & 100 & 33.6 & 0.8 & $0.4-1.3$ \\
\hline Very active & 41 & 27.5 & 103 & 34.6 & 0.7 & $0.4-1.1$ \\
\hline Missing & 1 & .7 & 4 & 1.3 & & \\
\hline
\end{tabular}

^Adjusted RR and 95\% CIs were derived from conditional logistic regression, taking into account matching on age, sex, and respondent type and adjusting for smoking status. Test for trend $\mathrm{p}=0.3$. †Inactive means that in previous year subject did not engage in any leisure time physical activity. Somewhat active means subject engaged in physical activity, but less than or equal to the median value among all case patients and control subjects with some physical activity during previous year. The median was $584.9 \mathrm{kcal} /$ week. Very active means more than the median value. similar whether considering the traditional case-control analysis (RR 11.6) or the case cross over analysis (RR 15.0). We are not aware of other studies that have examined this question with these types of analyses, but these findings are consistent with previous descriptive reports. In a study from Rochester, $\mathrm{MN}$, $\mathrm{USA}^{12}$ activity at the time of haemorrhage was recorded for 84 patients with subarachnoid haemorrhage. Forty per cent of the bleeds occurred during periods of physical or emotional stress. Tsementzis et $a l^{11}$ found that among 557 patients with stroke, subarachnoid haemorrhage $(n=194)$ occurred significantly more often during sexual intercourse, sporting activity, and toileting when compared with intracerebral haemorrhage and cerebral infarction. In the Cooperative Study, two thirds of 2288 case patients with aneurysmal subarachnoid haemorrhage were related to physical activity, emotional strain, trauma, or surgical operation. ${ }^{13}$ Another study found that strenuous physical activity was associated with $25 \%$ of patients with aneurysmal subarachnoid haemorrhage compared with $14 \%$ of patients with non-aneurysmal subarachnoid haemorrhage.$^{14}$

Although long term regular physical activity over the 12 months before the reference time was associated with a lower risk for subarachnoid haemorrhage, this association did not reach significance. This finding is consistent with previous findings examining the protective nature of regular physical activity against stroke. ${ }^{1} 24-71525$ Only two studies have considered this question specifically for subarachnoid haemorrhage. The Honolulu Heart Program used an estimate of current 24 hour habitual physical activity to prospectively study the impact of baseline physical activity on subarachnoid haemorrhage in men. ${ }^{15}$ In that study, men were divided into equal tertiles of "inactive," "partially active," and "active." The study found an excess of subarachnoid haemorrhage in inactive older men (ages 55 to 68). For haemorrhagic stroke, which included intracerebral as well as subarachnoid haemorrhage, a greater than threefold excess of haemorrhage was present among inactive compared with active older men, after controlling for 
hypertension, diabetes, and left ventricular hypertrophy. Another study found no relation between subarachnoid haemorrhage and physical activity, but included only 14 patients with subarachnoid haemorrhage and assessed physical activity with a crude four point scale. ${ }^{26}$ Studies with large sample sizes and detailed measures of physical activity are needed to clarify the protective potential of habitual physical activity level against subarachnoid haemorrhage.

The association between acute physical activity and subarachnoid haemorrhage is likely mediated through hypertension induced by exertion. Hypertension has been documented as a risk factor for subarachnoid haemorrhage in longitudinal, ${ }^{27-29}$ casecontrol, ${ }^{30-33}$ and ecological studies. ${ }^{1134} 35$ One study showed that the probability of intracranial aneurysm rupture increases with increased intra-aneurysmal pressure, which is the same as systemic arterial pressure. ${ }^{36}$ When the stress on the wall of an aneurysm exceeds wall strength aneurysmal rupture occurs. A study of the formation and rupture of intracranial aneurysms showed the importance of properties of the aneurysm wall and flow dynamics through the aneurysm, which are influenced by heart rate and blood pressure. ${ }^{37}$ Exercise is associated with a rapid rise in systolic blood pressure due to an increase in cardiac output. ${ }^{38}$ During defecation, micturition, and other postural activities the predominant physiological response is a Valsalva manoeuvre. ${ }^{39}$ During the course of this manoeuvre, arterial blood pressure rises and intracranial cerebrospinal fluid pressure drops, creating a large transmural pressure gradient that has been implicated in the pathogenesis of aneurysmal rupture. ${ }^{40}$ Physical activity has also been found to activate the fibrinolytic system. ${ }^{41-44}$ This haemostatic change may also play a part in the initiation or progression of subarachnoid haemorrhages. The possible protective nature of long term regular physical activity is likely mediated through improved cardiovascular conditioning, leading to lower baseline blood pressure and attenuated acute rise in blood pressure and heart rate from acute physical activity. ${ }^{45}$

The study has several strengths and limitations in its ability to determine the relation between acute and baseline physical activity and subarachnoid haemorrhage. Case patients and control subjects came from a defined geographical population and were asked detailed questions about their physical activity. Such questionnaires have been found to be accurate estimates of physical fitness. ${ }^{20}$ The current study was able to collect physical activity data that were more sensitive and quantifiable than that obtained in many other studies. Information about exposures was obtained from proxies for about half the case patients and their matched control subjects due to death or disability from their bleed. The comparison of responses from index and proxy control subjects showed good reliability for broad indi- cators of physical activity such as whether or not they were engaged in recreational physical activity in the past 12 months and whether they were inactive, active in only non-vigorous activities, or active in vigorous activities. ${ }^{24}$ However, only moderate reliability was found for detailed physical activity measures such as minutes of exercise/week and average kcal expended/week in recreational activity. The odds ratios obtained from proxy data were slightly biased toward the null compared with those obtained from index subject data, which may in part explain our inability to find a significant protective effect of long term regular physical activity.

Another potential limitation relates to recall bias. We asked subjects to recall their activities at a specific time. For the case patients the time was the onset of their subarachnoid haemorrhage. Control subjects lacked such an anchoring event. Consequently, we only required them to recall events from the same time of day and day of week as for their matched case patient, but in the week before their interview. Such physical activity recall surveys have been shown to be reliable and valid, particularly for recalling vigorous physical activity. ${ }^{46}$ Despite these efforts, the case patients and their proxies may have recalled with more details and with greater accuracy the events around the reference time than the control subjects.

Given our concern that differential recall might bias the results of our traditional case-control analysis, we also performed a case cross over analysis. This technique involves only information from case patients, whereby each patient serves as his or her own control. It was developed to identify transient effects of exposures, such as physical activity, on the risk of diseases with acute onset, such as subarachnoid haemorrhage. As with the more traditional case-control analysis, the case cross over analysis indicated that vigorous physical activity increased the risk of subarachnoid haemorrhage. These results add to the evidence indicating that the case cross over method is useful when the exposure in question is highly intermittent. The freedom of the case cross over method from confounding between subjects makes it uniquely suited for the study of physical activity, which may be subject to many personal factors, such as the frequency of exercise, emotional states at the time of exercise, and preferences for exercise at a particular time of day.

In this study, vigorous physical activity was associated with an acutely increased risk of spontaneous subarachnoid haemorrhage but was present in only a few patients. Although a regular exercise programme may reduce the overall risk of stroke, perhaps including subarachnoid haemorrhage, the risk of bleed seems to be increased during vigorous physical activity.

This study was supported in part by grant RO1 NS22690 from the National Institute of Neurological Disorders and Stroke, Bethesda, MD, USA. We thank Dr Thomas Koepsell for his helpful comments on the manuscript. 


\section{Appendix}

Case cross over comparison of patients' usual frequency of vigorous physical activity with presence of vigorous physical activity during hazard period - namely, the 15 minutes before the onset of the subarachnoid haemorrhage

Number of cases with vigorous physical activity during hazard period

Algebraic sum of 15 minute blocks of non-vigorous or no physical activity over the prior year in patents who reported vigorous physical activity during hazard period (numerator)

Algebraic sum of 15 minute blocks of vigorous physical activity over the prior year in patients who did not report vigorous physical activity during hazard period (denominator)

Relative risk $(95 \% \text { confidence interval })^{\star}$

4

9226

$15.0(4.3-52.2)$

*Mantel-Haenszel estimate of the relative risk of having a subarachnoid haemorrhage during a period of vigorous physical activity compared with a period of non-vigorous or no physical activity.

1 Wannamethee G, Shaper AG. Physical activity and stroke in British middle aged men. BMF 1992;304:597-601.

2 Salonen JT, Puska P, Tuomilehto J. Physical activity and risk of myocardial infarction, cerebral stroke and death: a longitudinal study in eastern Finland. Am $\mathcal{F}$ Epidemiol 1982;115: 526-37.

3 Paffenberger RS Jr, Laughlin ME, Gima AS, et al. Work activity of longshoremen as related to death from coronary heart disease and stroke. N Engl f Med 1970;282:1109-14

4 Gillum RF, Mussolino ME, Ingram DD. Physical activity and stroke incidence in women and men: the NHANES I epidemiologic follow-up study. Am f Epidemiol 1996;143: $860-9$

5 Kiely DK, Wolf PA, Cupples LA, et al. Physical activity and stroke risk: the Framingham study. Am $\mathcal{f}$ Epidemio 1994;140:608-20.

6 Herman B, Schmitz PI, Leyten AC, et al. Multivariate logistic analysis of risk factors for stroke in Tilburg, The Netherlands. Am f Epidemiol 1983;118:514-25.

7 Shinton R, Sagar G. Lifelong exercise and stroke. $B M \mathcal{F}$ 1993;307:231-4.

8 Menotti A, Keys A, Blackburn H, et al. Twenty-year stroke mortality and prediction in 12 cohorts of the seven Countries study. Int f Epidemiol 1990;19:309-15.

9 Lee IM, Paffenbarger RS Jr. Physical activity and stroke incidence: the Harvard alumni health study. Stroke 1998;29:2049-54.

10 Sacco RL, Gan R, Boden-Albala B, et al. Leisure-time physical activity and ischemic stroke risk: the northern Manhattan stroke study. Stroke 1998;29:380-7.

11 Tsementzis SA, Gill JS, Hitchcock ER, et al. Diurnal variation of and activity during the onset of stroke. Neurosurgery 1985;17:901-4.

12 Phillips LH, Whisnant JP, O'Fallon OM, et al. The unchanging pattern of subarachnoid hemorrhage in a community. Neurology 1980;30:1034-40.

13 Locksley HB. Natural history of subarachnoid hemorrhage, intracranial aneurysms and arteriovenous malformations: based on 6368 case patients in the cooperative study. In: Sahs AL, Perret GE, Locksley HB, et al, eds. Intracranial aneurysms and subarachnoid hemorrhage. Philadelphia: JB Lippincott, 1969:37-45.

14 Penrose R, Storey P. Emotional disturbance and subarachnoid hemorrhage. Psychother Psychosom 1970;18:321-5

15 Abbott RD, Rodriguez BL, Burchfiel CM, et al. Physical activity in older middle-aged men and reduced risk of stroke: the Honolulu heart program. Am $\mathcal{F}$ Epidemol 1994; 139:881-93.

16 Longstreth WT Jr, Nelson LM, Koepsell TD, et al. Cigarette smoking, alcohol use, and subarachnoid hemorrhage. Stroke 1992;23:1242-9.

17 Longstreth WT Jr, Nelson LM, Koepsell TD, et al. Clinical course of spontaneous subarachnoid hemorrhage: a population-based study in King County, Washington. Neurology 1993;43:712-18.

18 Ainsworth BE, Haskell WL, Leon AS, et al. Compendium of physical activities: classification of energy costs of human physical activities. Med Sci Sports Exerc 1993;25:71-80.

19 Taylor HL, Jacobs DR, Schucker B, et al. A questionnaire for the assessment of leisure time physical activities. 7 Chron Dis 1978;31:741-55.

20 Lamb KL, Brodie DA. Leisure-time physical activity as an estimate of physical fitness: a validation study. $\mathcal{F}$ Clin Epidemiol 1991;44:41-52.

21 Statistics and Epidemiology Research Corporation and Cytel Software Corporation. EGRET Reference Manual. Seattle: EGRET, 1990.

22 Maclure $M$. The case-crossover design: a method for studying transient effects on the risk of acute events. Am f Epidemiol 1991;133:144-53.

23 Rothman KJ. Modern epidemiology. Boston: Little, Brown, 1986.

24 Nelson LM, Longstreth WT Jr, Koepsell TD, et al. Completeness and accuracy of interview data from proxy respondents: demographic, medical, and life-style factors. Epidemiology 1994;5:204-17.
25 Lee I-M, Hennekens $\mathrm{CH}$, Berger K, et al. Exercise and risk of stroke in male physicians. Stroke 1999;30:1-6.

26 Harmsen P, Rosengren A, Tsipogianni A, et al. Risk factors for stroke in middle-aged men in Goteborg, Sweden. Stroke 1990;21:223-9.

27 Knekt P, Reunanen A, Aho K, et al. Risk factors for subarachnoid hemorrhage in a longitudinal population study. F Clin Epidemiol 1991;44:933-9.

28 Iso $\mathrm{H}$, Jacobs DR, Wentworth $\mathrm{D}$, et al. Serum cholesterol evels and 6 year mortality from stroke in 350977 men screened for the multiple risk factor intervention trial. $N$ Engl f Med 1989;320:904-10.

29 Yano K, Reed DM, Maclean CJ. Serum cholesterol and hemorrhagic stroke in the Honolulu heart program. Stroke $1989 ; 20: 1460-5$.

30 Toftdahl DB, Torp-Pedersen C, Engel UH, et al. Hypertension and left ventricular hypertropy in patients with spontaneous subarachnoid hemorrhage. Neurosurgery 1995;37:235-9.

31 Longstreth WT Jr, Nelson LM, Koepsell TC, et al. Subarachnoid hemorrhage and hormonal factors in women: a population-based case-control study. Ann Intern Med 1994;121:168-73.

32 Bonita R. Cigarette smoking, hypertension and the risk of subarachnoid hemorrhage: a population-based casecontrol study. Stroke 1986;17:831-5.

33 Inman WHW. Oral contraceptives and fatal subarachnoid hemorrhage. BMF 1979;ii:1468-70.

34 Gallerani M, Portaluppi F, Maida G, et al. Circadian and circannual rhythmicity in the occurrence of subarachnoid hemorrhage. Stroke 1996;27:1793-7.

35 Kelly-Hayes M, Wolf PA, Kase CS, et al. Temporal patterns of stroke onset: the Framingham study. Stroke 1995;26: $1343-7$

36 Ferguson GG. Physical factors in the initiation, growth, and rupture of human intracranial saccular aneurysms. $\mathcal{F}$ Neurosurg 1972;37:666-77.

37 Chitanvis SM, Hademenos G, Powers WJ. Hemodynamic assessment of the development and rupture of intracranial aneurysms using computational simulations. Neurol Res 1995; 17:426-34.

38 McArdle WD, Katch FI, Katch VL. Exercise physiology: energy, nutrition, and human performance. Philadelphia: Lea and Febiger, 1981:204-6.

39 Littler WA, Honour AJ, Sleight P. Direct arterial pressure, pulse rate and electrocardiogram during micturition and defecation in unrestricted man. Am Heart f 1974;88:20510

40 Schievink WI, Karemaker JM, Hageman LM, et al. Circumstances surrounding aneurysmal subarachnoid hemorrhage. Surg Neurol 1989;32:266-72.

41 Schneider SH, Kim HC, Khachadurian AK, et al. Impaired fibrinolytic response to exercise in type II deabetes: effects of exercise and physical training. Metabolism 1988;37:924-

42 Cushman M, Yanez D, Psaty BM, et al. Association of fibrinogen and coagulation factors VI and VIII with cardiovascular risk factors in the elderly: the cardiovascular health study. Am f Epidemiol 1996;143:665-76.

43 Drygas WK. Changes in blood platelet function, coagulation, and fibrinolytic activity in response to moderate, exhaustive, and prolonged exercise. Int F Sports Med 1988; 9:67-72.

44 van den Burg PJM, Hospers JEH, van Vliet M, et al. Unbalanced haemostatic changes following strenuous physical exercise: a study in young sedentary males. Eur Heart $\mathcal{f}$ 1995:16:1995-2001.

45 Shaper AG, Wannamethee G. Physical activity and ischaemic heart disease in middle-aged British men. Br Heart $\mathcal{f}$ 1991;66:384-94.

46 Laporte RE, Montoye HJ, Caspersen CJ. Assessment of physical activity in epidemiologic research: problems and prospects. Public Health Rep 1985;8:253-87. 